\section{RMD Open}

Rheumatic \& Musculoskeletal Diseases

\title{
Comparative analyses of responsiveness
} between the Rheumatoid Arthritis Impact of Disease score, other patientreported outcomes and disease activity measures: secondary analyses from the ARCTIC study

\author{
Karen Holten, ${ }^{1,2}$ Joseph Sexton, ${ }^{1}$ Tore K Kvien, ${ }^{1,2}$ Anna-Birgitte Aga, ${ }^{1}$ \\ Espen A Haavardsholm ${ }^{1,2}$
}

To cite: Holten K, Sexton J, Kvien TK, et al. Comparative analyses of responsiveness between the Rheumatoid Arthritis Impact of Disease score other patient-reported outcomes and disease activity measures: secondary analyses from the ARCTIC study. RMD Open 2018;4:e000754. doi:10.1136/ rmdopen-2018-000754

- Prepublication history for this paper is available online. To view these files, please visit the journal online (http://dx.doi. org/10.1136/rmdopen-2018000754).

A-BA and EAH are shared last authors.

Received 28 June 2018 Revised 29 August 2018 Accepted 22 September 2018

\section{Check for updates}

(c) Author(s) (or their employer(s)) 2018. Re-use permitted under CC BY-NC. No commercial re-use. See rights and permissions. Published by BMJ.

${ }^{1}$ Department of Rheumatology, Diakonhjemmet Hospital, Oslo, Norway

${ }^{2}$ Faculty of Medicine, University of Oslo, Oslo, Norway

Correspondence to Karen Holten; karenholten@gmail.com

\section{ABSTRACT}

Objective To evaluate the responsiveness of the Rheumatoid Arthritis Impact of Disease (RAID) score compared with other patient-reported outcome measures (PROMs), inflammatory markers and clinical disease activity measures in patients with early rheumatoid arthritis (RA).

Methods Disease-modifying antirheumatic drug-naïve patients with RA with short disease duration were included in the treat-to-target ARCTIC trial and followed for 24 months. The responsiveness of the RAID score was evaluated using standardised response mean (SRM) and relative efficiency (RE) with respect to tender joints by Ritchie Articular Index (RAl). SRMs and REs were also calculated for other PROMs, inflammatory markers and clinical outcome measures. An SRM with value above 0.80 was considered high.

Results 230 patients with RA were included. The mean \pm SD symptom duration was $7.1 \pm 5.4$ months and the baseline mean \pm SD RAID score was $4.49 \pm 2.14$. At 3 months of follow-up, the mean $\pm S D$ change score for RAID was $-2.25 \pm 1.98$ and the SRM $(95 \% \mathrm{Cl})-1.13(-1.33$ to $-0.96)$. The RAID score showed high responsiveness both at 3 and 6 months ( $\mathrm{SRM} \geq 0.80$ ) and was more sensitive in detecting change than the reference, tender joints assessed by RAl.

Conclusions The RAID score proved to be highly responsive to change in patients with RA with short disease duration who followed a treat-to-target strategy. The RAID score was more efficient in detecting change than the reference (RAl) as well as most other PROMs.

\section{INTRODUCTION}

Patient-reported outcome measures (PROMs) provide valuable information about the impact of disease from a patient perspective and are considered as important as conventional disease activity and clinical outcome

\section{Key messages}

What is known about this subject?

- Responsiveness is an important quality in patient-reported outcome measures.

- Further validation of the responsiveness of the Rheumatoid Arthritis Impact of Disease (RAID) score has been suggested.

What does this study add?

- The RAID score showed high responsiveness to change compared with conventional disease activity measures and other patient-reported outcome measures.

How might this impact on clinical practice?

- The RAID score should be considered for use in clinical rheumatoid arthritis trials.

measures. They support patient-centred care and shared decision-making between patient and rheumatologist regarding treatment, in alignment with European League Against Rheumatism (EULAR) recommendations. ${ }^{1-3}$

Efforts have been put into development and validation of rheumatoid arthritis (RA) PROMs in order to achieve valid outcomes. ${ }^{4-9}$ A prior EULAR initiative developed a patient-derived composite response index for RA for use in clinical trials, called the Rheumatoid Arthritis Impact of Disease (RAID) score. ${ }^{5}$ The RAID score includes the domains sleep disturbances, fatigue, coping and physical and emotional well-being, in addition to pain and physical disability, which are traditionally assessed. Further validation of the responsiveness of the RAID score has been suggested. ${ }^{610}$ 
The objective of this study was to assess the changes in the RAID score in patients with early RA within the first 6 months of intensive disease-modifying antirheumatic drug (DMARD) treatment, and to evaluate the responsiveness of RAID after 3 and 6 months, compared with other PROMs and conventional disease activity measures.

\section{METHODS}

\section{Patients and study design}

This study used data from the ARCTIC trial (ClinicalTrials.gov identifier: NCT01205854). ${ }^{11}$ All patients fulfilled the American College of Rheumatology (ACR) / EULAR classification criteria for RA, had symptom duration less than 2 years and were DMARD naive. Patients were randomised 1:1 to a treat-to-target strategy with or without the use of ultrasound examination. All patients received treatment according to the same escalating DMARD treatment algorithm, in accordance with current EULAR treatment recommendations. ${ }^{211}$ Results from the ARCTIC trial showed no significant differences in clinical and radiographic outcomes between the two groups and both treatment groups were merged in the current analyses.

\section{Assessments}

Patients were assessed at 13 visits within 24 months. PROMs included the RAID score, the Patient-Reported Outcomes Measurement Information System 20-item Physical Function short form (PROMIS PF-20, range 20-100), the 36-item Short Form Health Survey (SF-36, $0-100$ ) with calculations of physical and mental component summaries (PCS and MCS), fatigue Visual Analogue Scale (VAS, 0-100 mm) and joint pain VAS. Other assessments included swollen joint count (0-44), tender joint count (Ritchie Articular Index (RAI) with a graded (0-3) assessment of the tenderness of 26 joints (0-78)), erythrocyte sedimentation rate (ESR, $\mathrm{mm} /$ hour), $\mathrm{C}$ reactive protein (CRP, mg/L) and patient and physician global assessment of disease activity VAS. Disease Activity Score (DAS, 0-10) was also assessed, a four-variable composite score of 44-swollen joint count, RAI, ESR and patient global assessment.

The RAID score assesses the impact of disease on seven domains. Each RAID domain is measured on a simple numeric rating scale from 0 (best) to 10 (worst) and is assigned a weight in the sum score. Pain is weighted $21 \%$, functional disability $16 \%$, fatigue $15 \%$ and sleep disturbance, physical and emotional well-being as well as coping all $12 \% .{ }^{56}$ An absolute and relative Minimal Clinically Important Improvement (MCII) of at least 3 points or more than $50 \%$ has been proposed, along with a Patient Acceptable Symptom State (PASS) of maximum $2 .{ }^{10}$ Suggested cut-off values for levels of impact of disease are RAID $\leq 3$ (remission), RAID $>3$ and $\leq 4$ (low impact of disease), RAID $>4$ and $\leq 6$ (moderate impact of disease), and RAID $>6$ (high impact of disease) ${ }^{12}$

\section{Statistical analyses}

To evaluate the responsiveness of the different outcome measures, standardised response mean (SRM) was calculated as the ratio between the mean change score and the SD of the mean change score, expressed as $S R M=\frac{\text { mean change score }}{S D_{\text {change score }}}$ at 3 and 6 months of follow-up. ${ }^{13}$ Bootstrapping techniques (5000 replications) were applied to calculate the $95 \%$ CI of the SRMs. The threshold values for effect size suggested by Jacob Cohen were used to interpret the magnitude of the SRM and values above $0.20,0.50$ and 0.80 represent small, moderate and large responsiveness, respectively. ${ }^{14}$ The relative efficiencies (REs) with SE were calculated with respect to tender joints (RAI) at 3 months from baseline. RE equals the square of the ratio between the SRM of the outcome and the SRM of RAI and is given by the formula $R E=\left(\frac{S R M_{1}}{S R M_{2}}\right)^{2}$ $.{ }^{1516} \mathrm{An} \mathrm{RE}>1$ suggests that a measure is more efficient in detecting change than the RAI. ${ }^{15}$ Tender joints, in this case by RAI, is an outcome measure which reflects inflammation and disease activity and based on these capacities it was selected as anchor for the RE analyses.

Baseline data were examined for floor effect, which can occur when more than $15 \%$ of the patients achieve the lowest possible score. The percentage of missing data was small and no imputation was performed.

Statistical analyses were performed using IBM SPSS Statistics V.24 and R V.3.0.2.

\section{RESULTS}

Baseline demographics, clinical characteristics and PROMs including the seven RAID domains from the 230 included patients are presented in table 1. At baseline, the mean \pm SD DAS and RAID scores were $3.46 \pm 1.17$ and $4.49 \pm 2.14$, respectively, indicating a moderate disease activity in this cohort. One patient $(0.4 \%)$ reported a RAID score of 0 at baseline. No floor effect was identified.

The mean change scores and SRM values of the outcome measures after 3 and 6 months are shown in table 2. After 3 months, there was a marked treatment response in all measures, and the same tendency was observed at 6 months. The $-1.95 \pm 1.09$ points improvement in the DAS at 6 months led to a mean \pm SD DAS of $1.52 \pm 0.89$, which indicates an average change from moderate disease activity to remission. ${ }^{11} 17$ The percentage of patients in DAS remission was 48 and 62 at 3 and 6 months of follow-up, equivalent of 99 and 131 patients, respectively.

The mean \pm SD change of the RAID score at 3 and 6 months was $-2.25 \pm 1.98$ and $-2.39 \pm 1.98$, respectively, which led to mean \pm SD scores of $2.28 \pm 1.84$ and $2.08 \pm 1.78$ at 3 and 6 months, respectively, which reflects that the group on average achieved a level of remission according to the suggested cut-off values. At 3 and 6 months, 34\% and $40 \%$ of the patients had reached the suggested absolute MCII of 3 or more and $56 \%$ and $58 \%$ the relative MCII of $50 \%$ or more. Moreover, $53 \%$ and $56 \%$ of the patients reported a RAID score of 2 or less at 3 and 6 months, which is the suggested PASS. 
Table 1 Baseline characteristics (values are mean \pm SDs unless stated otherwise)

\begin{tabular}{|c|c|}
\hline Characteristics & $\mathrm{N}=\mathbf{2 3 0}$ \\
\hline Women N (\%) & $141(61)$ \\
\hline Anti-CCP positive N (\%) & $189(82.2)$ \\
\hline Age & $51.4 \pm 13.7$ \\
\hline Time since patient reported first swollen joint, months & $7.1 \pm 5.40$ \\
\hline RAID total & $4.49 \pm 2.14$ \\
\hline RAID pain & $5.32 \pm 2.40$ \\
\hline RAID functional disability & $4.76 \pm 2.53$ \\
\hline RAID fatigue & $4.46 \pm 2.77$ \\
\hline RAID sleep disturbance & $3.90 \pm 3.08$ \\
\hline RAID physical well-being & $4.73 \pm 2.40$ \\
\hline RAID emotional well-being & $3.91 \pm 2.44$ \\
\hline RAID coping & $3.73 \pm 2.35$ \\
\hline Disease Activity Score & $3.46 \pm 1.17$ \\
\hline Erythrocyte sedimentation rate & $24.5 \pm 18.6$ \\
\hline C reactive protein, median (IQR) & $7.00(3.00,18.0)$ \\
\hline Swollen joints* & $10.5 \pm 7.51$ \\
\hline Tender joints $†$ & $8.82 \pm 7.34$ \\
\hline Patient global assessment VAS & $49.8 \pm 24.4$ \\
\hline Physician global assessment VAS & $40.6 \pm 20.6$ \\
\hline PROMIS physical function & $39.08 .5 \pm 8.68$ \\
\hline Fatigue VAS & $40.4 \pm 28.7$ \\
\hline Joint pain VAS & $47.8 \pm 24.1$ \\
\hline SF-36 physical component summary & $36.3 \pm 9.50$ \\
\hline SF-36 mental component summary & $49.1 \pm 10.6$ \\
\hline
\end{tabular}

Disease Activity Score (0-10), <1.6 (remission), $\geq 1.6-2.4$ (low disease activity), >2.4-3.7 (moderate disease activity), >3.7 (high disease activity). Erythrocyte sedimentation rate ( $\mathrm{mm} /$ hour, 1-140).

${ }^{*}$ Assessment of 44 joints (0-44).

†Ritchie Articular Index (0-78).

CCP, cyclic citrullinated peptide; PROMIS, Patient-Reported Outcome Information System (20-100); RAID, Rheumatoid Arthritis Impact of Disease (0-10); SF-36, 36-item Short Form Health Survey (0-100); VAS, Visual Analogue Scale (mm, 0-100).

DAS, RAID, RAI, PROMIS PF-20, joint pain, SF-36 PCS, physician and patient global assessment and swollen joint count all showed high responsiveness to change (SRM $\geq 0.80$ ). ESR and CRP showed moderate responsiveness to change (SRM $>0.5)$ while fatigue VAS and SF-36 MCS showed low responsiveness (SRM $<0.5)$ (table 2).

The RE in relation to tender joints (RAI) after 3 and 6 months are illustrated in figure 1. DAS, physician global assessment and swollen joint count showed the highest efficiencies in detecting change. After 6 months, the RE of the RAID score increased slightly, which led to a slightly better performance than patient global assessment and joint pain VAS. The least efficient outcomes were ESR, CRP, fatigue VAS and SF-36 MCS.

\section{DISCUSSION}

Our study of patients with RA with short disease duration and followed by treat-to-target strategy found the RAID score to be highly responsive to change and efficient in detecting change compared with several other PROMs.

At 3 and 6 months, more than half of the patients reported a RAID score of 2 or less, which is the suggested PASS and also indicates remission as proposed by Salaffi et al. ${ }^{12}$ In comparison, $48 \%$ and $62 \%$ of the ARCTIC population achieved DAS remission at 3 and 6 months of follow-up.

More than half of the patients in the ARCTIC population achieved the suggested relative MCII of $50 \%$ or more after 3 months while a smaller proportion had an absolute improvement of 3 points or more. An absolute change of 3 points or more in an individual or a population with moderate disease activity level at baseline and short symptom duration, such as in the ARCTIC trial, might not be realistic to achieve.

The outcome with the highest relative sensitivity to change was DAS. Three of the DAS components, swollen joints, patient global assessment and joint pain, were 
Table 2 Mean change \pm SD and standardised response mean (SRM) with 95\% Cls for patient-reported outcomes and conventional disease activity measures from baseline to 3 months and from baseline to 6 months ordered by decreasing SRM at 3 months

\begin{tabular}{|c|c|c|c|c|}
\hline & \multicolumn{2}{|c|}{ 0-3 months } & \multicolumn{2}{|l|}{ 0-6 months } \\
\hline & $\begin{array}{l}\text { Change } \\
\text { mean } \pm S D\end{array}$ & $\begin{array}{l}\text { SRM } \\
(95 \% \mathrm{Cl})\end{array}$ & $\begin{array}{l}\text { Change } \\
\text { mean } \pm S D\end{array}$ & $\begin{array}{l}\text { SRM } \\
(95 \% \mathrm{Cl})\end{array}$ \\
\hline Disease Activity Score & $-1.71 \pm 1.04$ & $-1.63(-1.89$ to -1.42$)$ & $-1.95 \pm 1.09$ & $-1.80(-2.04$ to -1.60$)$ \\
\hline Physician global assessment VAS & $-26.2 \pm 19.2$ & $-1.37(-1.54$ to -1.22$)$ & $29.2 \pm 20.7$ & $-1.41(-1.58$ to -1.27$)$ \\
\hline Swollen joints* & $-8.86 \pm 6.89$ & $-1.28(-1.46$ to -1.14$)$ & $-9.63 \pm 7.41$ & $-1.30(-1.46$ to -1.17$)$ \\
\hline Patient global assessment VAS & $-28.3 \pm 24.2$ & $-1.17(-1.35$ to -1.02$)$ & $-30.2 \pm 25.2$ & $-1.20(-1.38$ to -1.05$)$ \\
\hline PROMIS physical function & $9.14 \pm 7.91$ & $1.16(1.01$ to 1.32$)$ & $9.98 \pm 8.48$ & 1.18 (1.02 to 1.36$)$ \\
\hline Joint pain VAS & $-27.7 \pm 24.4$ & $-1.14(-1.31$ to -0.98$)$ & $-29.5 \pm 25.2$ & $-1.17(-1.35$ to -1.02$)$ \\
\hline RAID & $-2.25 \pm 1.98$ & $-1.13(-1.33$ to -0.96$)$ & $-2.39 \pm 1.98$ & $-1.21(-1.38$ to -1.06$)$ \\
\hline SF-36 physical component summary & $8.99 \pm 9.02$ & $1.00(0.84$ to 1.18$)$ & $9.19 \pm 9.47$ & 0.97 (0.83 to 1.14$)$ \\
\hline Tender joints $†$ & $-5.75 \pm 6.03$ & $-0.95(-1.12$ to -0.80$)$ & $-6.33 \pm 6.30$ & $-1.01(-1.15$ to -0.88$)$ \\
\hline Erythrocyte sedimentation rate & $-10.9 \pm 15.0$ & $-0.73(-0.83$ to -0.63$)$ & $-11.7 \pm 16.5$ & $-0.71(-0.84$ to -0.59$)$ \\
\hline $\mathrm{C}$ reactive protein & $-9.68 \pm 18.4$ & $-0.53(-0.62$ to -0.43$)$ & $-10.8 \pm 19.5$ & $-0.55(-0.63$ to -0.48$)$ \\
\hline Fatigue VAS & $-13.3 \pm 29.3$ & $-0.45(-0.60$ to -0.32$)$ & $-16.0 \pm 29.8$ & $-0.54(-0.68$ to -0.40$)$ \\
\hline SF-36 mental component summary & $3.89 \pm 10.6$ & 0.37 (0.23 to 0.52$)$ & $3.02 \pm 10.8$ & $0.28(0.15$ to 0.43$)$ \\
\hline
\end{tabular}

${ }^{*}$ Assessment of 44 joints $(0-44)$.

†Ritchie Articular Index (0-78).

RAID, Rheumatoid Arthritis Impact of Disease (0-10); VAS, Visual Analogue Scale (mm, 0-100); PROMIS, Patient-Reported Outcome Information System (20-100);SF-36, 36-item Short Form Health Survey (0-100).

highly responsive as single domains. The outcomes with the highest relative responsiveness all reflect physical aspects of the disease, whereas the RAID score includes emotional well-being and coping and still seems to show a high efficiency in detecting change.

Patient global assessment (PGA) and RAID are both global patient-reported indexes and both measures are equally responsive to change, according to this study. PGA is already incorporated in the EULAR/ACR core set of outcome measures for RA. The question whether the RAID score could replace the patient global assessment has been raised. ${ }^{6}$ Some considerations in this regard would be that the PGA is less time consuming to perform compared with the RAID score. If a global assessment with no differentiation is satisfying, then the PGA should be sufficient. However, RAID provides more specific details about the impact of disease.

The data imply that the RAID score was more efficient in detecting change than the other multidimensional PROMs, SF-36 PCS and MCS and PROMIS physical function after 6 months. Compared with these outcomes, the RAID score separates itself in the sense that it incorporates the traditional health-related domains as well as sleep, fatigue, well-being and coping that patients with RA perceive as important. ${ }^{18-20}$ Furthermore, the RAID score distinguishes itself as a disease-specific outcome compared with the generic SF-36 and PROMIS physical function.

For an outcome to be able to detect treatment effect or any change over time, it needs to be responsive. There are a variety of statistical approaches to measuring responsiveness and there is no consensus yet about which approach is the best. ${ }^{162122}$ Measuring the magnitude of change detected by an instrument is one approach and multiple effect size indices are applied for this purpose. There is some evidence to suggest that using the SD of the change score (SRM) rather than the SD of the baseline score (ES) is more informative because it includes the variety of the change scores, ${ }^{13}$ which is why we chose to use SRM and not ES. It was as well a factor that SRM had been used to measure the responsiveness in the finalisation and validation study of the RAID score and we wanted to be able to compare the results.

In conclusion, this early RA intervention study provides support for the responsiveness of the RAID score. According to the EULAR/ACR recommendations for reporting results in clinical trials, assessing changes is important. ${ }^{23}$ The changes in the RAID score corresponded well with the changes in the DAS with regard to the proportion of patients in remission after 6 months. The RAID score was more efficient in detecting change than the reference (RAI) as well as other PROMs. The RAID score is a highly responsive patient-reported composite index which, with the suggested cut-off values, MCII and PASS should be considered for intervention studies in patients with RA. Further research should assess the responsiveness to change of the RAID score regarding the performance in RA flares. 


\section{A Relative efficiencies 3 months}

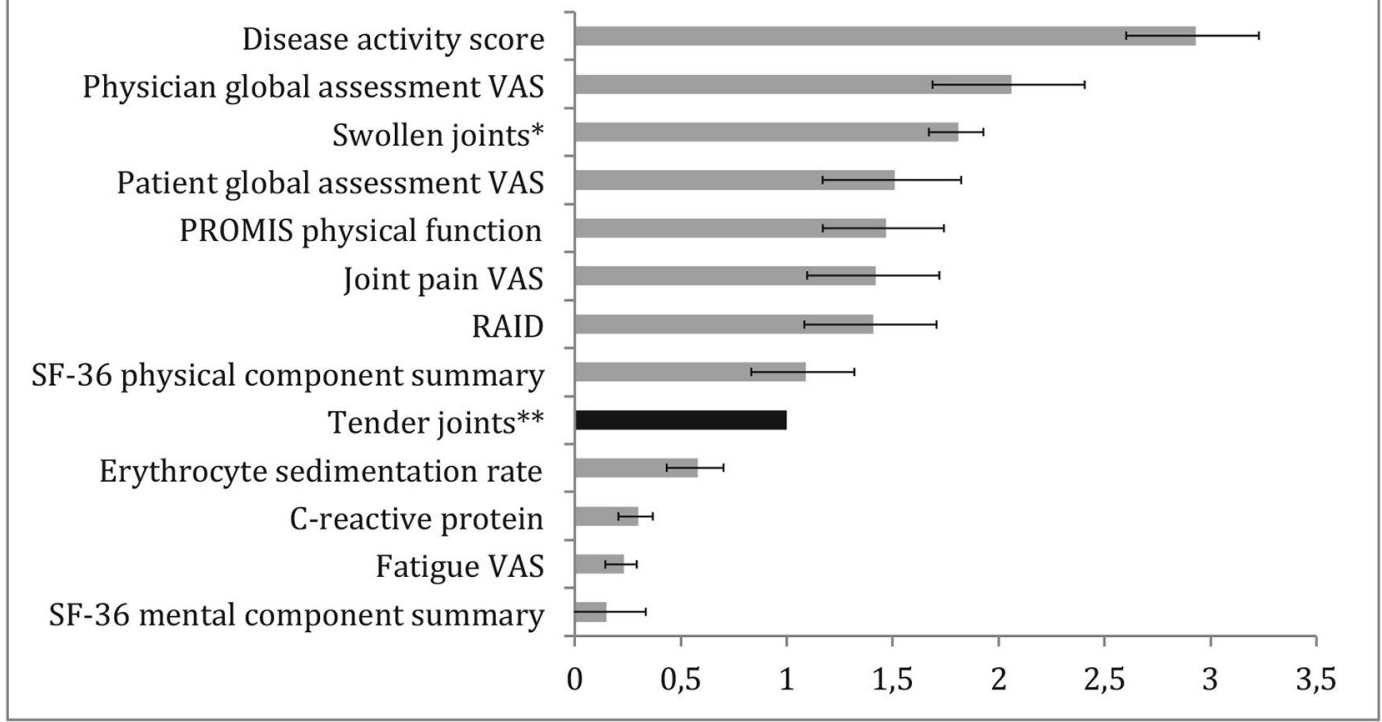

\section{B Relative efficiencies 6 months}

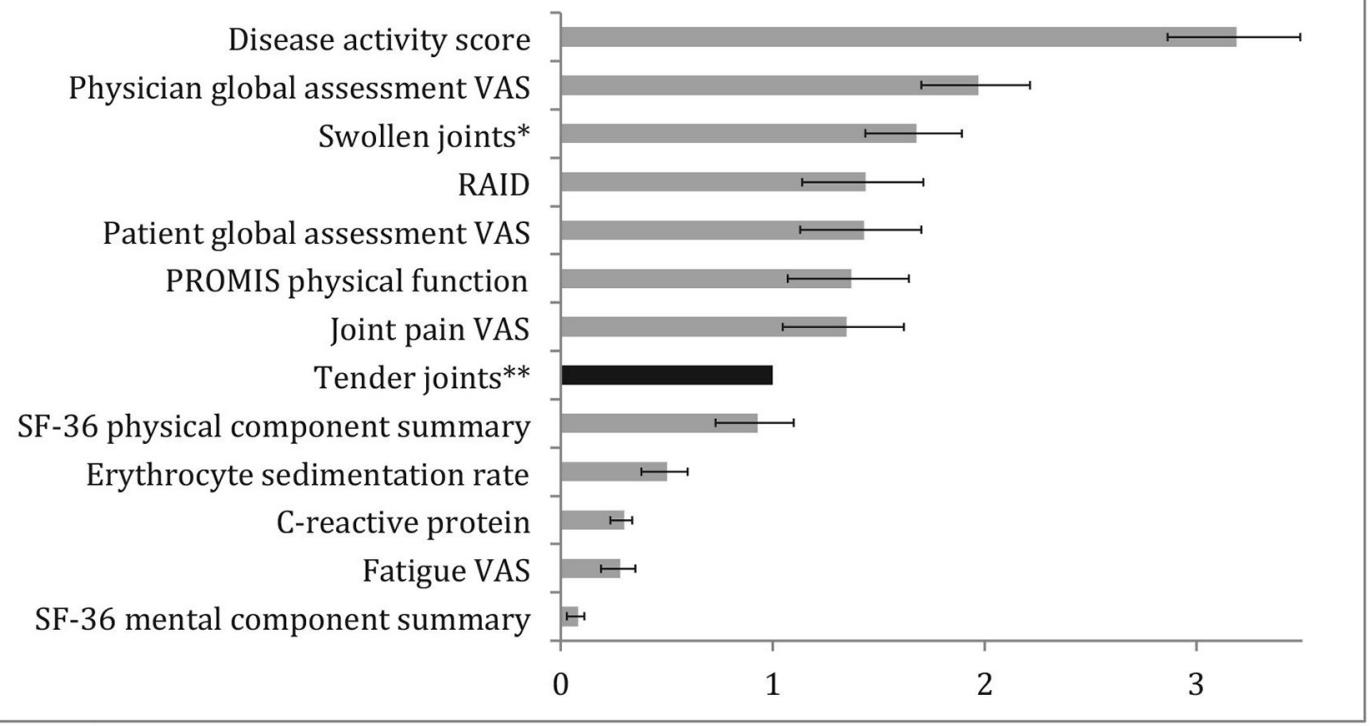

Figure 1 Relative efficiencies to tender joints (Ritchie Articular Index, RAI) of the various outcomes reflecting disease activity after 3 months (A) and 6 months (B) of follow-up (tender joints (RAI)=reference with a relative efficiency of 1.00). PROMIS, Patient-Reported Outcome Information System; RAID, Rheumatoid Arthritis Impact of Disease; SF-36, 36-item Short Form Health Survey; VAS, Visual Analogue Scale. *Assessment of 44 joints. ${ }^{\star *}$ Ritchie Articular Index.

Acknowledgements The authors wish to thank the patients for participating in this study and the ARCTIC investigators: Hallvard Fremstad, Tor Magne Madland, Åse Stavland Lexberg, Hilde Haukeland, Erik Rødevand, Christian Høili, Hilde Stray, Anne Lindter Noraas, Dag Magnar Soldal and Gunnstein Bakland. Parts of the work from this manuscript have been presented at the EULAR Congress 2018; Annals of the Rheumatic Diseases, volume 77, year 2018, page 1824

Contributors KH designed the current study, analysed and interpreted data, and wrote the report. JS analysed and interpreted data, and reviewed the manuscript. TKK designed the ARCTIC study, contributed to the current study design, interpreted data and reviewed the manuscript. A-BA and EAH designed the current study and the ARCTIC study, recruited and enrolled participants, collected, analysed and interpreted data, and reviewed the manuscript. All authors have approved the final draft and vouch for the accuracy and completeness of the data and analyses.

Funding The ARCTIC study has received grants from the Norwegian Research Council, the South-East Health Region in Norway, the Norwegian Rheumatism Association and investigator-initiated research grants from AbbVie, Pfizer, MSD, Roche and UCB.

Competing interests $\mathrm{KH}$ : none. JS: none. TKK has received consultancy honorariums from AbbVie, Bristol-Myers Squibb, Celltrion, Epirus, Hospira, Merck-Serono, MSD, Orion Pharma, Pfizer, Roche and UCB. A-BA has received consultancy honorariums from UCB, AbbVie, Eli Lilly and Pfizer. EAH has received 
research funding from Pfizer, UCB, Roche, MSD and AbbVie for the submitted work; honorariums as a speaker from Pfizer, UCB, Roche and AbbVie; honorariums for development of educational material from Pfizer; and has sat on advisory boards for Pfizer, Eli Lilly and Celgene.

Patient consent Not required.

Ethics approval REK Sør-Øst C.

Provenance and peer review Not commissioned; externally peer reviewed.

Data sharing statement № additional data are available.

Open access This is an open access article distributed in accordance with the Creative Commons Attribution Non Commercial (CC BY-NC 4.0) license, which permits others to distribute, remix, adapt, build upon this work non-commercially, and license their derivative works on different terms, provided the original work is properly cited, appropriate credit is given, any changes made indicated, and the use is non-commercial. See: http://creativecommons.org/licenses/by-nc/4.0

\section{REFERENCES}

1. Gossec L, Dougados M, Dixon W. Patient-reported outcomes as end points in clinical trials in rheumatoid arthritis. RMD Open 2015;1:e000019.

2. Smolen JS, Landewé R, Bijlsma J, et al. EULAR recommendations for the management of rheumatoid arthritis with synthetic and biological disease-modifying antirheumatic drugs: 2016 update. Ann Rheum Dis 2017;76:960-77.

3. Fautrel B, Alten R, Kirkham B, et al. Call for action: how to improve use of patient-reported outcomes to guide clinical decision making in rheumatoid arthritis. Rheumatol Int 2018;38:935-47.

4. Heiberg T, Austad C, Kvien TK, et al. Performance of the Rheumatoid Arthritis Impact of Disease (RAID) score in relation to other patientreported outcomes in a register of patients with rheumatoid arthritis. Ann Rheum Dis 2011;70:1080-2.

5. Gossec L, Dougados M, Rincheval N, et al. Elaboration of the preliminary Rheumatoid Arthritis Impact of Disease (RAID) score: a EULAR initiative. Ann Rheum Dis 2009;68:1680-5.

6. Gossec L, Paternotte S, Aanerud GJ, et al. Finalisation and validation of the rheumatoid arthritis impact of disease score, a patient-derived composite measure of impact of rheumatoid arthritis: a EULAR initiative. Ann Rheum Dis 2011;70:935-42.

7. Wells G, Li T, Maxwell L, et al. Responsiveness of patient reported outcomes including fatigue, sleep quality, activity limitation, and quality of life following treatment with abatacept for rheumatoid arthritis. Ann Rheum Dis 2008;67:260-5.

8. de Vet HCW, Terwee CB, Mokkink LB. Measurement in medicine: a practical guide. Cambridge University Press, 2011.
9. Fitzpatrick RDC, Buxton M, Jones D. Evaluating patient-based outcome measures for use in clinical trials: a review. Health Technology Assessment 1998.

10. Dougados M, Brault Y, Logeart I, et al. Defining cut-off values for disease activity states and improvement scores for patient-reported outcomes: the example of the Rheumatoid Arthritis Impact of Disease (RAID). Arthritis Res Ther 2012:14:R129.

11. Haavardsholm EA, Aga AB, Olsen IC, et al. Ultrasound in management of rheumatoid arthritis: ARCTIC randomised controlled strategy trial. BMJ 2016;354:i4205.

12. Salaffi F, Di Carlo M, Vojinovic J, et al. Validity of the rheumatoid arthritis impact of disease (RAID) score and definition of cut-off points for disease activity states in a population-based European cohort of patients with rheumatoid arthritis. Joint Bone Spine 2018;85:317-22.

13. Katz JN, Larson MG, Phillips CB, et al. Comparative measurement sensitivity of short and longer health status instruments. Med Care 1992;30:917-25.

14. Cohen J. Statistical power analysis for the behavioral sciences. 2nd edn. NJ: Laurence Erlbaum, 1988.

15. Liang $\mathrm{MH}$, Larson MG, Cullen KE, et al. Comparative measurement efficiency and sensitivity of five health status instruments for arthritis research. Arthritis Rheum 1985;28:542-7.

16. Terwee CB, Dekker FW, Wiersinga WM, et al. On assessing responsiveness of health-related quality of life instruments: guidelines for instrument evaluation. Qual Life Res 2003;12:349-62.

17. Fransen J, Stucki G, van Riel PLCM. Rheumatoid arthritis measures: Disease Activity Score (DAS), Disease Activity Score-28 (DAS28), Rapid Assessment of Disease Activity in Rheumatology (RADAR), and Rheumatoid Arthritis Disease Activity Index (RADAl). Arthritis \& Rheumatism 2003;49(S5):S214-24.

18. Kirwan JR, Hewlett SE, Heiberg T, et al. Incorporating the patient perspective into outcome assessment in rheumatoid arthritisprogress at OMERACT 7. J Rheumatol 2005;32:2250-6.

19. Ahlmén M, Nordenskiöld U, Archenholtz B, et al. Rheumatology outcomes: the patient's perspective. A multicentre focus group interview study of Swedish rheumatoid arthritis patients. Rheumatology 2005;44:105-10.

20. Carr A, Hewlett S, Hughes R, et al. Rheumatology outcomes: the patient's perspective. J Rheumatol 2003;30:880.

21. Middel B, van Sonderen E, Berrie M. Statistical significant change versus relevant or important change in (quasi) experimental design: some conceptual and methodological problems in estimating magnitude of intervention-related change in health services research. Int J Integr Care 2002;2:e15.

22. Beaton DE, Bombardier C, Katz JN, et al. A taxonomy for responsiveness. J Clin Epidemiol 2001;54:1204-17.

23. Aletaha $\mathrm{D}$, Landewe $\mathrm{R}$, Karonitsch $\mathrm{T}$, et al. Reporting disease activity in clinical trials of patients with rheumatoid arthritis: EULAR/ACR collaborative recommendations. Arthritis Rheum 2008:59:1371-7. 